\title{
Distribution of the population and health projects of the Joint Fund in China between 2006 and 2019
}

\author{
Hongmei Zhou ${ }^{1 \#}$, Xiaoqiu Yang ${ }^{2 \#}$, Quan $\mathrm{Liu}^{3}, \mathrm{Jun} \mathrm{Pu}^{1}$, Rong Lei ${ }^{3}$ \\ ${ }^{1}$ Department of Cardiology, Renji Hospital, School of Medicine, Shanghai Jiao Tong University, Shanghai, China; ${ }^{2}$ Renji Hospital, School of \\ Medicine, Shanghai Jiao Tong University, Shanghai, China; ${ }^{3}$ The National Natural Science Foundation of China, Beijing, China \\ Contributions: (I) Conception and design: H Zhou, X Yang; (II) Administrative support: Q Liu; (III) Provision of study materials or patients: R Lei; \\ (IV) Collection and assembly of data: R Lei; (V) Data analysis and interpretation: J Pu; (VI) Manuscript writing: All authors; (VII) Final approval of \\ manuscript: All authors. \\ \#These authors contributed equally to this work. \\ Correspondence to: Rong Lei. The National Natural Science Foundation of China, Beijing, China. Email: leirong@nsfc.gov.cn; Jun Pu. Department of \\ Cardiology, Renji Hospital, School of Medicine, Shanghai Jiao Tong University, Shanghai, China. Email: pujun310@hotmail.com.
}

Background: The Joint Fund has explored the cooperation mechanism between the National Natural Science Foundation of China (NSFC) and local government, promoted the development of basic research, and created a new model system. The Joint Fund has had a huge influence on scientific and technological community, especially in the field of population and health.

Methods: Research materials and related data were drawn from the NSFC database. We used the search words "National Natural Science Foundation", "Joint Fund", population and health", and "medical codes" to obtain useful information and collect relevant data.

Results: From 2006 to 2019, the NSFC's Joint Fund awarded a total of 767.683 million Chinese Yuan to 590 projects, distributed in 9 local government Joint Funds and 1 enterprise Joint Fund within the field of population and health. And the NSFC-Guangdong Joint Fund has invested the most, followed by the NSFC-Yunnan Joint Fund. A total of 92 applicants' host institutions from 20 provinces and municipalities were funded by the Joint Fund in the field of population and health, of which Zhengzhou University received the largest number of projects (137), and Sun Yat-sen University received the largest amount of funding (CNY $76,230,000)$.

Conclusions: The Joint Fund has increased investment in the field of population and health in recent years. By analyzing the characteristics of population and health projects, we identified the NSFC-Guangdong Joint Fund and NSFC-Yunnan Joint Fund invested more, and Sun Yat-sen University and Zhengzhou University received more funding projects, which may help to guide future grant applications.

Keywords: National Natural Science Foundation of China (NSFC); Joint Fund; Population Health

Submitted Jul 16, 2021. Accepted for publication Sep 03, 2021.

doi: 10.21037/atm-21-4364

View this article at: https://dx.doi.org/10.21037/atm-21-4364

\section{Introduction}

The National Natural Science Foundation of China (NSFC) plays an important role in Chinese basic scientific research, greatly promoting the improvement of scientific and technological standards, and improving the rapid development of various basic research fields in China (1). In the early 1990s, in response to the pressing need for scientific and technological development, the NSFC established the Joint Fund to guide and integrate social resources into basic research, promote resource sharing, and encourage multi-party cooperation (2). The joint fund is one of the important components of the National Natural Science Foundation of China, which looks to develop innovation in basic Chinese research, has drawn particular 


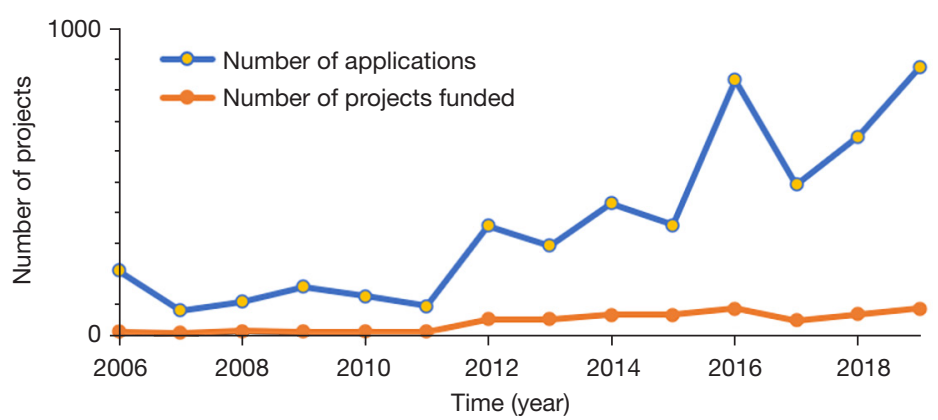

Figure 1 The number of applications and funding projects in the field of population and health of the Joint Fund increased significantly from 2006 to 2019.

interest from scientists and researchers.

The Joint Fund successfully explored the cooperation mechanism between the NSFC and the local government, NSFC and the enterprise, NSFC and the industry and other relevant departments, promoted the development of basic research, and created a new model system. The Joint Fund has had a huge impact on the scientific and technological community (3). With the goal of combining national development needs with basic research, through continuous reform and innovation, the content of the Joint Fund is continuously updated and expanded.

Currently, the Joint Fund covers major well-being issues such as population and health, biology and agriculture, and environment and ecology, among which the population and health is one of the most critical fields. With the continuous improvement of people's living standards and the incremental lengthening of life expectancy, the issues surrounding population development and health needs have become increasingly prominent (4). Based on this situation, the Joint Fund's investment in basic research in the field of population and health has increased annually (3). In addition to the department of Medical and Life Sciences in the NSCF, the Joint Fund has also increased funding for research projects on major diseases with high morbidity, fatality and disability, such as cardiovascular and cerebrovascular diseases and tumors. This article includes a retrospective analysis which was conducted on the funding in the field of population and health projects from 2006 to 2019, and was aimed at providing a reference for formulating future plans for the Joint Fund; and achieving the best investment benefits in the field of population and health.

\section{Methods}

Research materials and related data were obtained from the NSFC database, using the search keywords "National Natural Science Foundation", "Joint Fund", "population and health", and "medical codes" to obtain useful information and collect relevant data.

\section{Statistical analysis}

All the original data were put into the excel table and analyzed. Statistical analysis was undertaken using SPSS 22.0. Comparisons were done with the Chi-square test and Fisher's exact test for categorical parameters, while with Student's $t$-test or analysis of variance (ANOVA) test for continuous variables. A 2 -sided $\mathrm{P}<0.05$ was considered to be statistically significant.

\section{Results}

Funding in the field of population and bealth projects in the foint Fund from 2006 to 2019

In the past 14 years, the number of population and health projects funded by the Joint Fund and the amount of funding have been increasing annually, and the number of applications for scientific research personnel has also increased significantly, as shown in Figure 1 and Figure 2.

From 2006 to 2019, the Joint Fund had funded 1,794 projects. Among them, there were a total of 590 population and health projects, including 304 (51.53\%) Fostering Program Projects, followed by 274 (46.44\%) Key Program Projects. The total funding of the Joint Fund from 2006 to 2019 was 2634.863 million Chinese Yuan (CNY). From this, the funding received for population and health projects was 767.683 million CNY, of which 595.01 million CNY for Key Program projects and 126.273 million CNY for Fostering Program projects, as shown in Table 1. 


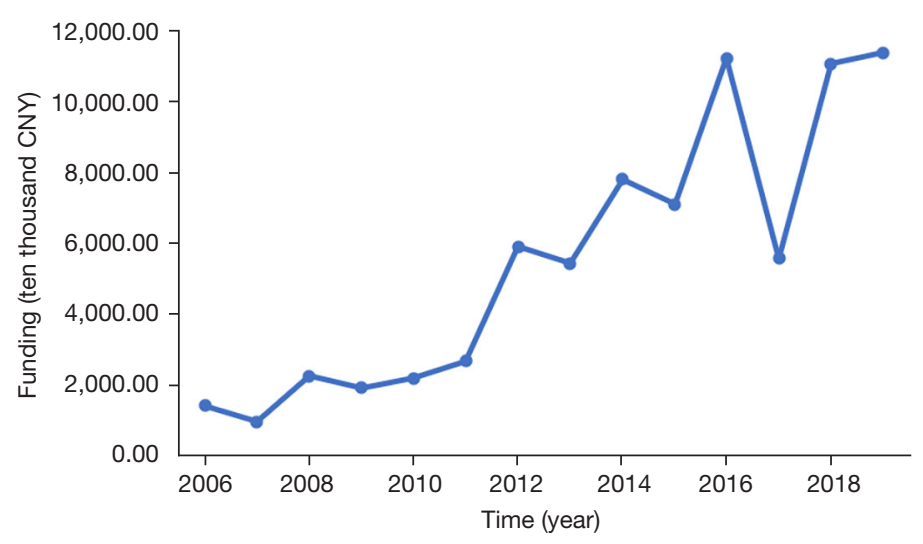

Figure 2 The funding of Joint Fund in the population and health increased year by year from 2006 to 2019.

Table 1 Funding of the Joint Fund in the field of population and health from 2006 to 2019

\begin{tabular}{|c|c|c|c|c|}
\hline Type of projects & \multicolumn{2}{|c|}{ Funding in the field of population and health in the Joint Fund } & \multicolumn{2}{|c|}{ Funding of the Joint Fund } \\
\hline Key program projects & 274 & 59,501 & 918 & 204,502 \\
\hline Fostering program project & 304 & $12,627.3$ & 816 & $37,850.3$ \\
\hline Fostering local talents & 10 & 940 & 51 & 4,820 \\
\hline Center project & 1 & 2,520 & 1 & 2,520 \\
\hline Supercomputing special & 0 & 0 & 1 & 5,800 \\
\hline Total & 590 & $76,768.30$ & 1794 & $263,486.3$ \\
\hline
\end{tabular}

Fostering local talents belongs to Xinjiang local youth talent training projects, which is not representative.

There were 10 Fostering Local Talents projects with a total amount of 9.4 million $\mathrm{CNY}$, all of them located in Xinjiang. There was 1 Integrated Project and 1 Central Project, which received funding of 11.8 million $\mathrm{CNY}$ and 25.2 million CNY, respectively (Table 1).

\section{Distribution of funding in the field of population and bealth among different foint Funds}

The Joint Fund consists of a local government Joint Fund, enterprise Joint Fund, and industry Joint Fund. Our study indicates that there was a total of 9 local governments Joint Funds and 1 enterprise Joint Found fund population and health projects. The investment in the field of population and health was mainly from local government Joint Funds. Among them, the NSFC-Guangdong Joint Fund granted 196.16 million CNY, accounting for $25.55 \%$ of the total funding in the field of health, followed by the NSFC-
Yunnan Joint Fund with an amount of 160.48 million CNY (20.90\%), and then the NSFC-Henan Joint Fund with a funding amount of 13.9503 million CNY (18.17\%) (Figure 3).

\section{Distribution of funding projects according to geographic region}

As shown in Figure 4, applicants in 20 provinces and municipalities received funding between 2006 and 2019 . Henan Province received the most funding with 270 (45.76\%) projects. This was followed by $99(16.78 \%)$ projects in Guangdong, and 61 (10.34\%) projects in Yunnan.

As shown in Figure 5, in terms of the amount of funding received, Guangdong was at the top, with a total funding amount of 202.73 million CNY, followed by Henan, with 135.233 million CNY, and then Yunnan, with 124.37 million CNY. 


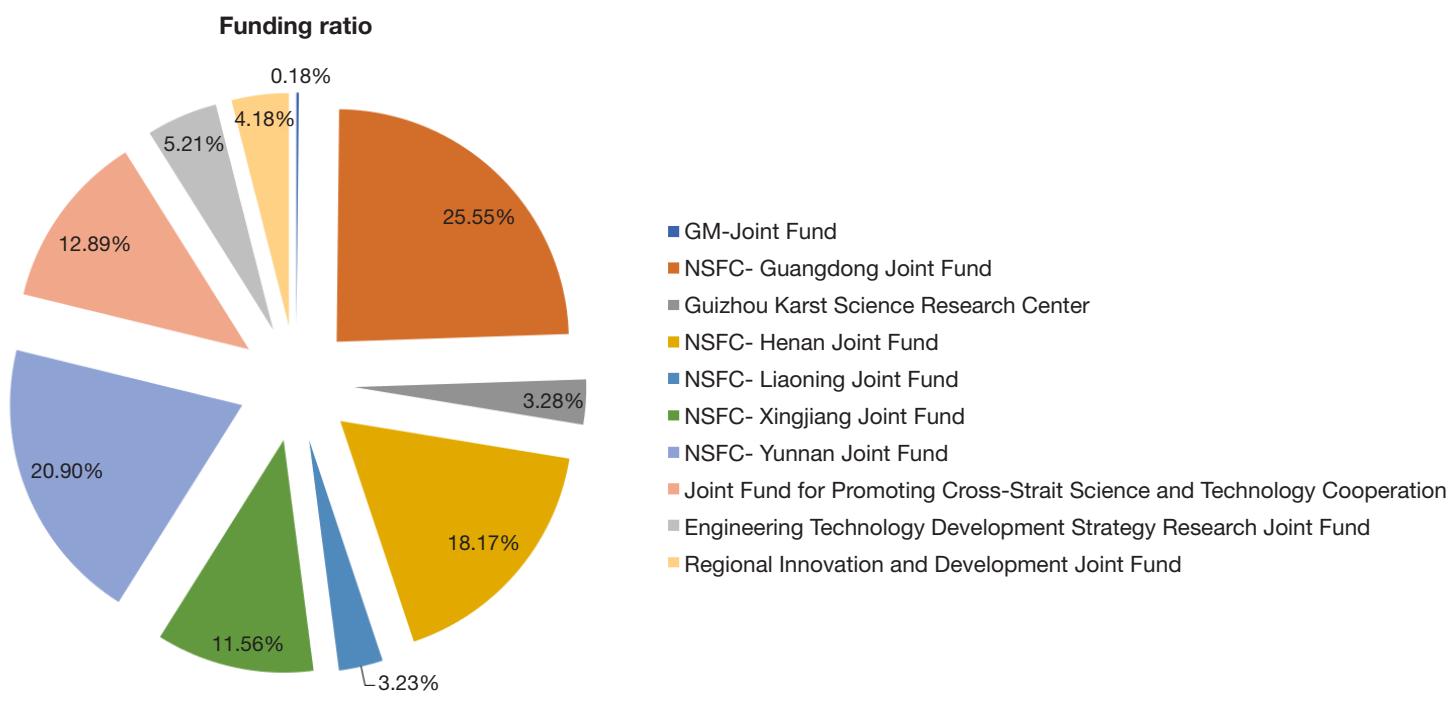

Figure 3 The investment of various Joint Funds in the field of population and health from 2006 to 2019. The pie chart shows that the NSFC-Guangdong Joint Fund has invested the most, followed by the NSFC-Yunnan Joint Fund. NSFC, National Natural Science Foundation China.

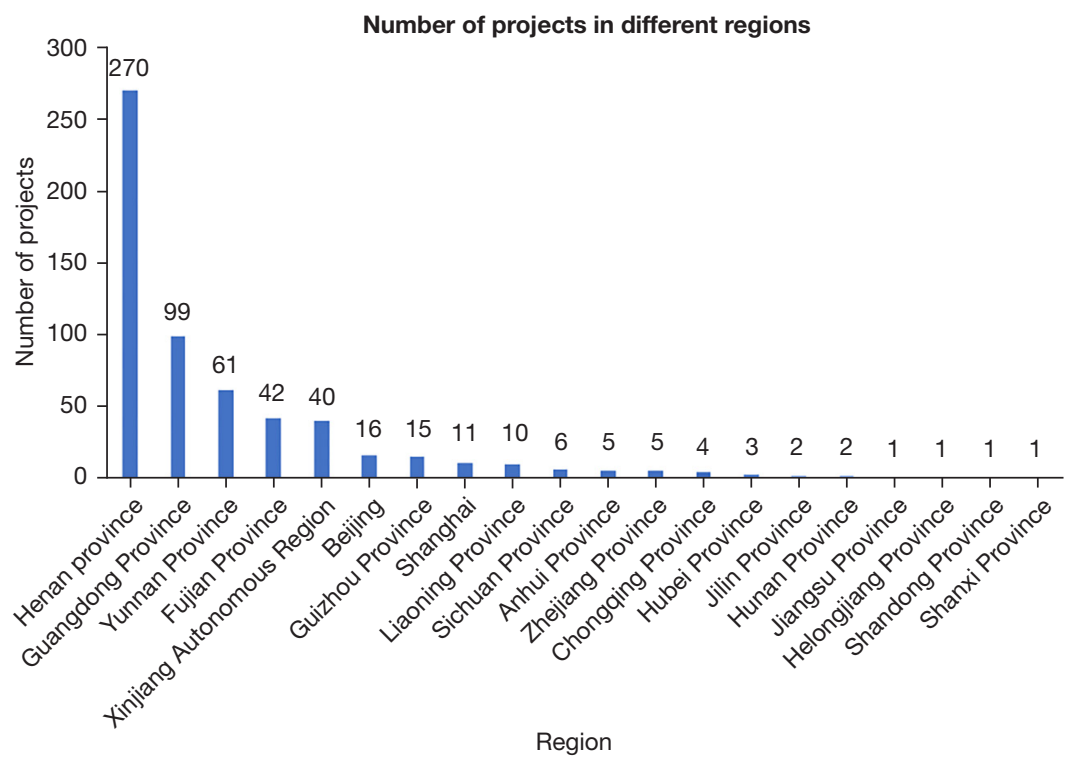

Figure 4 Number of projects in different region. Henan received funding for the most projects, followed by Guangdong.

\section{Applicants' bost institutions}

From 2006 to 2019, a total of 92 applicants' host institutions were funded by the Joint Fund in the field of population and health. Among them, 12 applicants' host institutions were supported for more than 10 projects. Zhengzhou University had the most funded projects, with a total of
137, accounting for $23.22 \%$, Xinxiang Medical College was second with 40 funded projects $(6.8 \%)$, and the third was Sun Yat-sen University, with 35 funded projects $(5.93 \%)$ (Figures 6).

Over the past 14 years, 18 applicants' host institutions have received more than 10 million CNY in funding. Among them, Sun Yat-sen University ranked first with 


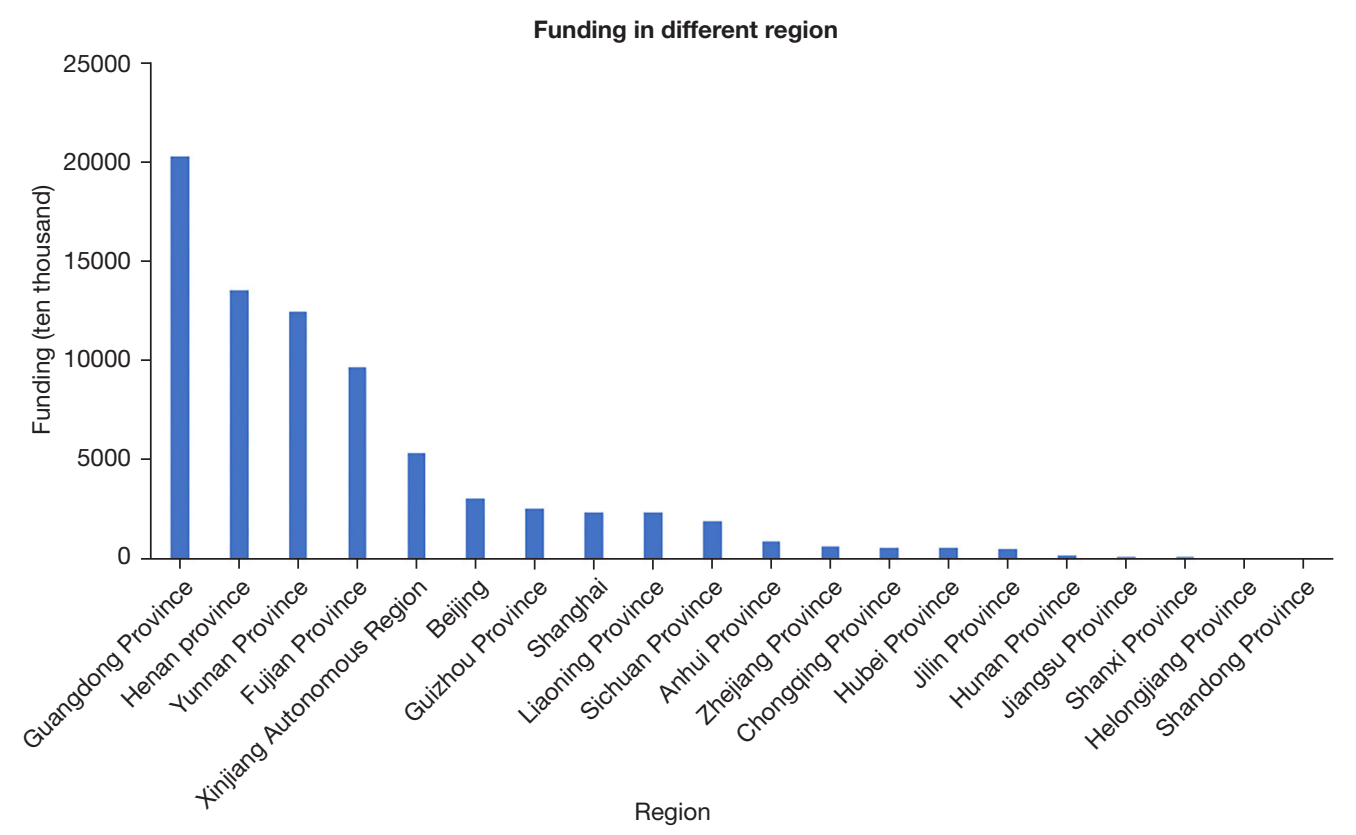

Figure 5 The total amount of funding received in the field of population and health in the Joint Fund in 2006 and 2019 . Among them, the total amount of funding received by the Guangdong Province was the highest, Henan was second highest, and Yunnan was third.

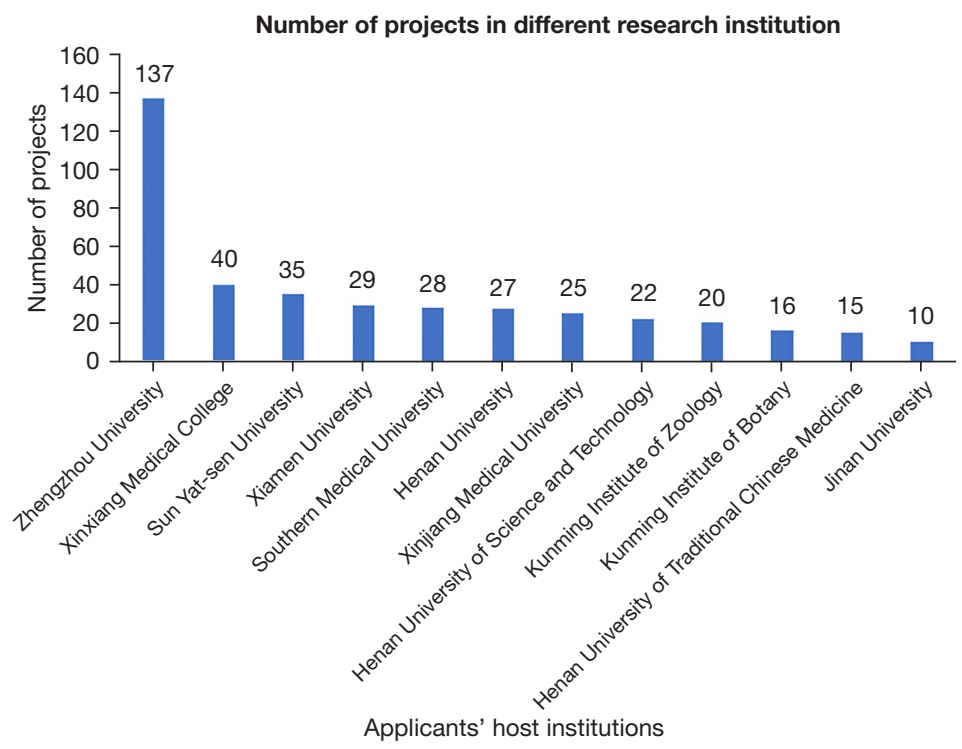

Figure 6 From 2006 to 2019, the distribution of the top 10 research institutions in the field of population and health in the Joint Fund. Among them, Zhengzhou University received the most, with grants for 137 projects.

a total of 76.23 million CNY in funding, Zhengzhou University ranked second with 72.99 million CNY, and Xiamen University ranked third with 65.23 million CNY, as shown in Figure 7.

\section{Discussion}

This study investigated grants delivered by the Joint Fund in the field of population and health projects. The Joint Fund's funding amount and number of projects in the field 


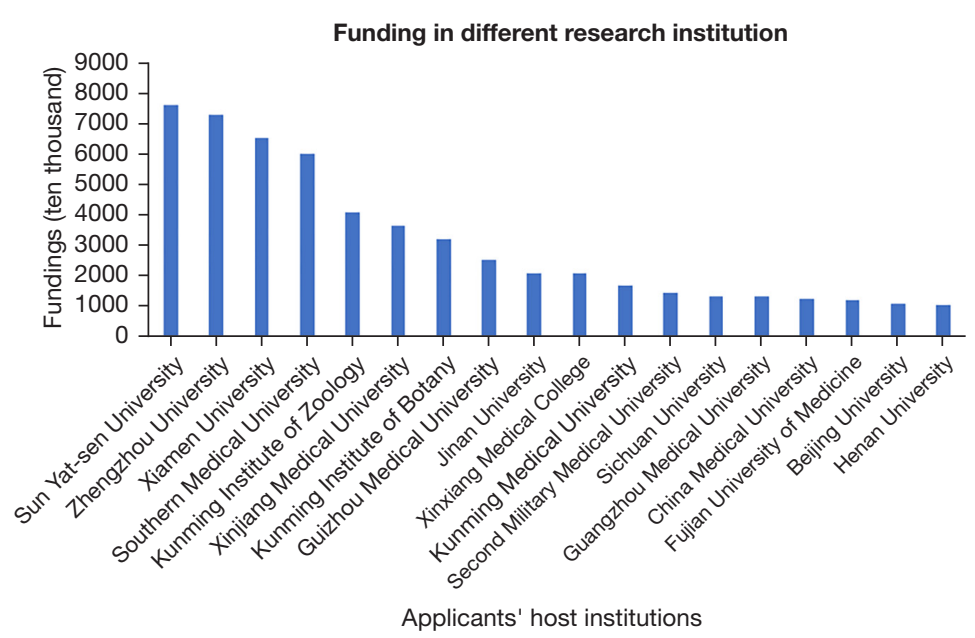

Figure 7 Applicants' host institutions that received more than 10 million CNY in the field of population and health of the Joint Fund from 2006 to 2019, among which Sun Yat-sen University received the most.

of population and health have increased significantly in the past 14 years. Most of the population and health projects of the Joint Fund were funded by the local governments Joint Fund. Funded projects mainly consisted of Key Program projects and Fostering Program projects. The funding covered 20 provinces, autonomous regions, and municipalities across the country, including in 92 applicants' host institutions.

The Joint Fund's investment in the field of population and health has maintained continuous growth, which is consistent with the government's guidance on medical care. As the life expectancy of the Chinese population increases, the demand for medical and health care also increases $(5,6)$. Therefore, increasing the volume of funding in the field of population and health is consistent with the health requirements of the people in China at this stage $(5,6)$. The funded projects have mainly focused on Fostering Program projects and Key Program projects, with the largest number being Fostering Program projects, which play a role of expansive coverage and cultivation of young talents. Only the NSFC-Henan Joint Fund has Fostering Program projects, and it is only for young researchers from scientific research institutes in Henan province, which suggests that young researchers in Henan province has more opportunities to apply and get fundings. The Key Program projects had the largest amount of funding, far exceeding that of other projects. Funding Key Program projects fosters in-depth research in the health field, and help to realize the greatest potential of scientific and technological talents and produce more research results. Notably, the average funding rate of $10-20 \%$ in the field of population and health of the Fostering Local Talents Project in Xinjiang, is slightly lower than the average funding rate of other Joint Funds, indicating that the funding distribution of population and health is more competitive than that of other fields.

This study found that in recent years, most of population and health projects had been funded by the local government and NSCF. Among them, the NSCFGuangdong Joint Fund invested 196.16 million CNY, which is one of the most prolific funds. This is related to the special economic status and strong financial strength of Guangdong (7). This study also found that Henan and Yunnan invested more in the field of population and health, indicating that the 2 local governments were more attentive to the field of population and health.

This study also found that the regions receiving the most funding were host institutions in Guangdong, followed by Henan and Yunnan, which was consistent with their investment. Strikingly, we found an interesting phenomenon that in the field of population and health, Guangdong received more funding than invested from 2006 to 2019, indicating that researchers in Guangdong are focusing on cross-research with other regions.

This study also found that the population and health field projects supported by the Joint Fund were more numerous, among which Zhengzhou University has applied for the largest number of projects. This is consistent with the NSCF-Henan Joint Fund's greater investment. We 
also found that Sun Yat-sen University received the largest amount of funding, which was consistent with the NSCFGuangdong Joint Found investment. At the same time, Guangdong was also the first region to establish a Joint Fund with the NSCF.

In short, by the description and analysis of the results of this study, researchers engaged in population health can clearly understand some of the characteristics of the Joint Fund, which is helpful for their application.

\section{Conclusions}

In order to meet Chinese population development and demands, the NSFC-local government Joint Fund has continuously increased investment in the field of population and health in recent years. An increasing number of universities and scientific research institutions are paying attention to the Joint Fund. By analyzing the characters of population and health projects from the Joint Fund, we have identified the NSFC-Guangdong and NSFC-Yunnan Joint Fund invested more funds, and Sun Yat-sen University and Zhengzhou University received more funding projects, which may help to guide future grant applications.

\section{Acknowledgments}

Funding: National Natural Science Foundation of China (81900373) and Outstanding Youth Training Funds of Shanghai Renji Hospital (PYIII-17-034).

\section{Footnote}

Conflicts of Interest: All authors have completed the ICMJE uniform disclosure form (available at https://dx.doi. org/10.21037/atm-21-4364). The authors have no conflicts of interest to declare.

Ethical Statement: The authors are accountable for all aspects of the work in ensuring that questions related to the accuracy or integrity of any part of the work are

Cite this article as: Zhou H, Yang X, Liu Q, Pu J, Lei R. Distribution of the population and health projects of the Joint Fund in China between 2006 and 2019. Ann Transl Med 2021;9(17):1388. doi: 10.21037/atm-21-4364 appropriately investigated and resolved.

Open Access Statement: This is an Open Access article distributed in accordance with the Creative Commons Attribution-NonCommercial-NoDerivs 4.0 International License (CC BY-NC-ND 4.0), which permits the noncommercial replication and distribution of the article with the strict proviso that no changes or edits are made and the original work is properly cited (including links to both the formal publication through the relevant DOI and the license). See: https://creativecommons.org/licenses/by-nc-nd/4.0/.

\section{References}

1. Zhu Z. Basic research must come first. An interview with Zuoyan Zhu, Vice President of the National Natural Science Foundation of China and member of the Chinese Academy of Sciences. Interviewed by Holger Breithaupt and Caroline Hadley. EMBO Rep 2004;5:442-5.

2. Liu $Y$, Gao Z, Wang H, et al. Analysis of projects funded by the National Natural Science Foundation of China during the years of 2014-2018. Ann Transl Med 2019;7:267.

3. Lei R, Liu Q, Wang Y, et al. Analysis of major programs in the field of health science funded by the National Natural Science Foundation of China between the years 2010 and 2018. Ann Transl Med 2019;7:268.

4. Yang G, Wang Y, Zeng Y, et al. Rapid health transition in China, 1990-2010: findings from the Global Burden of Disease Study 2010. Lancet 2013;381:1987-2015.

5. Yu P, Liu X, Wang J. Geriatric medicine in China: The past, present, and future. Aging Med (Milton) 2018;1:46-9.

6. Fang EF, Xie C, Schenkel JA, et al. A research agenda for ageing in China in the 21st century (2nd edition): Focusing on basic and translational research, long-term care, policy and social networks. Ageing Res Rev 2020;64:101174.

7. Yun Q. Politics, Profit and Digital Prospect: Guangdong Provincial Publishing Group as a Case. In: China's Publishing Industry. Cambridge, Mass.: Chandos Publishing, 2019; 221-256.

(English Language Editor: J. Jones) 